\title{
The Utilisability of Ground Hazelnut Shell as Filler in Polypropylene Composites
}

\author{
H. DEMIRER ${ }^{a, *}, \dot{I}$. KARTAL $^{a}$, A. YILDIRIM ${ }^{b}$ AND K. BÜYÜKKAYA ${ }^{c}$ \\ ${ }^{a}$ Marmara University, Faculty of Technology, 34720 Istanbul, Turkey \\ ${ }^{b}$ Demir Döküm, Bahçelievler, 34688 Istanbul, Turkey \\ ${ }^{c}$ Giresun University, 28049 Giresun, Turkey
}

\begin{abstract}
In Turkey, hazelnut shell is obtained in large quantities as an agricultural industry waste but usually used as heating material in houses. Hazelnut shell can be used as filler material in plastic composites due to its cellulosic structure. In this study, the utilisability of ground hazelnut shell in PP matrix composites investigated due to its relative hardness, characteristic color and availability. 5, 10, 15 , and $20 \%$ by weight ground hazelnut shell were mixed with PP matrix by extrusion and test samples prepared out of those mixtures by injection moulding. Tensile, the Izod impact, hardness, density, melt flow index, heat deflection and the Vicat softening point tests were performed on the samples. E modulus, hardness, heat deflection and the Vicat softening temperature values increased with the increased amount of ground hazelnut shell in polypropylene matrix. However, tensile strength, force at break, elongation at break, the Izod impact and melt flow index values decreased.
\end{abstract}

DOI: 10.12693/APhysPolA.134.254

PACS/topics: wood/plastic composites, polypropylene, hazelnut shell, mechanical properties

\section{Introduction}

Global awareness of environmental issues has resulted in the emergence of sustainable and environmentally friendly green materials, which are renewable resources based, recyclable and biodegradable. To develop green composite materials, natural fibres, such as jute, kenaf, hemp, flax, and sisal, have been utilised to replace conventional synthetic fibres. Green composites are the next generation of sustainable composite materials and combine natural fibres with various resins to make light and strong composites that are recyclable or biodegradable. The use of renewable resources reduces the needs for natural resources such as petrochemicals and minerals, resulting in less natural resources depletion effect on the earth. Green composites are generally referred to as having potential uses in sectors such as automotive and construction [1-4]. In this respect, various wood fibers, and even cellulose wastes such as ground wood waste, cereal straw and corncobs, have been used as fillers for plastics. Wood compares favorably with other available inorganic fillers such as glass fibers calcium carbonate and talc since it is inexpensive, readily available, and causes less machine wear in plastics processing equipment $[5,6]$. Wood/plastic composites (WPC) are a relatively new class of materials and one of the fastest growing sectors in the wood composites industry. WPCs made with woodpolypropylene are typically used in automotive, building applications and consumer products [7-10]. In Turkey, hazelnut shell is obtained in large quantities but usually used as heating material in houses. Hazelnut shell can

* corresponding author; e-mail: hdemirer@marmara.edu.tr also be used as filler material in plastic composites due to its cellulosic structure. In this study, the utilisability of ground hazelnut shell in PP matrix composites investigated due to its relative hardness, characteristic color and availability.

\section{Materials and method}

\subsection{Materials}

In this study, homopolymer polypropylene (PP MH418 polymer known as Petkim's petoplen) was used as matrix material. Polyethylene wax OX.PE WAX LE 262 produced by Innospec Leuna was supplied by ERAL Turkey to facilitate processing as a lubricant. The IRGANOX 1010 antioxidant (supplied by the Ciba Geigy Turkey) was used to minimize any possible oxidation during the mixing in the extruder and during the injection molding. The ground hazelnut shell used in this study was obtained from hazelnut known as "Giresun quality hazelnut".

\subsection{Preparation of composite specimens}

Hazelnut shell was ground in a traditional water mill. The PP/GHS (ground hazelnut shell) mixture produced in the extruder were dried at $100^{\circ} \mathrm{C}$ for $4 \mathrm{~h}$ before injection molding. Test specimens were obtained in accordance with ISO 527 using a Supermaster SM-60HC injection molding machine. PP/GHS mixing ratios was presented in Table I.

$\mathrm{PP} /$ GHS mixing ratios

TABLE I

\begin{tabular}{c|c|c|c|c|c}
\hline \hline Group & 1. & 2. & 3. & 4. & 5. \\
\hline PP [wt\%] & 100 & 95 & 90 & 85 & 80 \\
HS [wt\%] & 0 & 5 & 10 & 15 & 20
\end{tabular}




\subsection{Characterization}

Tensile tests were carried out according to ISO 527 using a ZWICK Z1010 model universal testing machine at a strain rate of $50 \mathrm{~mm} / \mathrm{min}$. Izod impact tests were performed according to EN ISO 180 using a CEAST impact testing equipment. For scanning electron microscopy (SEM) analysis, JEOL JSM-5910LV model SEM was used at $10 \mathrm{kV}$. Flow properties of the composites were determined by using a Zwick 4100 model MFI equipment following the standard EN 1133. HDT and Vicat softening point were determined by using a Ceast 6505 model testing equipment following standards ISO 307 and ISO 75 respectively. Shore D hardness test was carried out using a Zwick model hardness testing equipment.

\section{Results and discussion}

The test results of the samples obtained from PP/GHS mixtures were given in the following tables and figure. The effect of ground GHS content on the density and mechanical properties of the PP/GHS mixtures was given in Table II. As expected, the presence of GHS caused a slight increase in the density of mixtures. Tensile strength and elongation at break decreased with the increasing GHS content. On the other hand, increasing GHS content caused an increase in hardness and $E$ modulus. With the increasing ground GHS content, the Izod impact strength decreases. Since the HS is a relatively hard substance, decreased impact strengths were expected in the case of PP matrix. These results are in line with some inorganic fillers such as calcite andtalc [7].
Table III shows the results of the Vicat softening point and heat deflection temperatures measurements of the $\mathrm{PP} / \mathrm{GHS}$ composites. With the increasing GHS content, the Vicat temperature values increased to about $160^{\circ} \mathrm{C}$. With the increasing ground GHS content, HDT increased to about $66^{\circ} \mathrm{C}$. With the increasing ground GHS content, MFI values decreased from $6.0 \mathrm{~g} / 10 \mathrm{~min}$ to about $4.3 \mathrm{~g} / 10 \mathrm{~min}$. These results are in line with the literature [7].

A typical SEM image of GHS powders was presented in Fig. 1. As can be seen from the SEM image the hazelnut shell powder sizes varied between 0 and $100 \mu \mathrm{m}$.

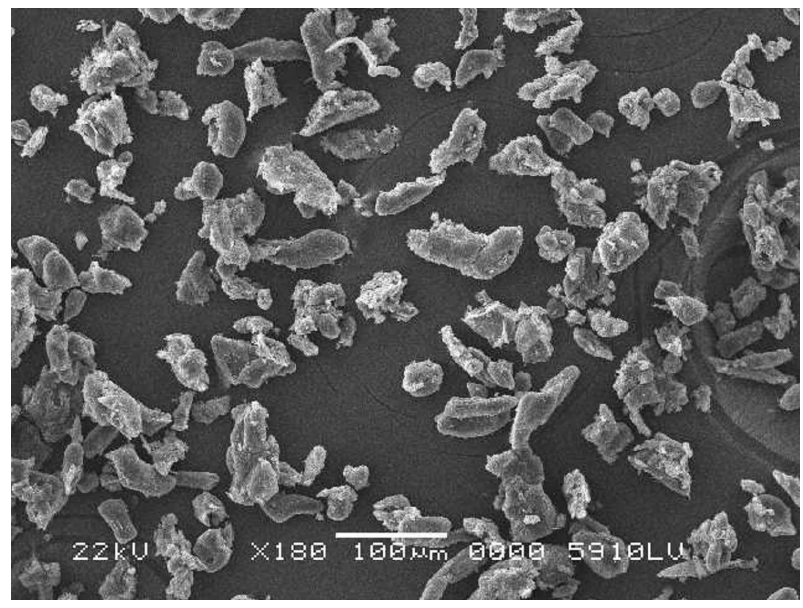

Fig. 1. A typical SEM image of GHS powders.

Results of density and mechanical tests of PP/GHS composites

TABLE II

\begin{tabular}{c|c|c|c|c|c|c}
\hline \hline GHS [wt\%] & $\begin{array}{c}\text { Tensile } \\
\text { strength [MPa] }\end{array}$ & $E$ modulus [MPa] & $\begin{array}{c}\text { Elongation } \\
\text { at break [\%] }\end{array}$ & $\begin{array}{c}\text { Hardness, } \\
\text { shore D }\end{array}$ & Density $\left[\mathrm{g} / \mathrm{cm}^{3}\right]$ & $\mathrm{Izod}\left[\mathrm{kJ} / \mathrm{m}^{2}\right]$ \\
\hline 0 & 30.84 & 869.05 & 47.84 & 74 & 0.9 & 3.37 \\
5 & 31.84 & 1236.29 & 13.88 & 74.5 & 0.918 & 2.87 \\
10 & 29.9 & 1336.42 & 7.91 & 75.8 & 0.935 & 2.67 \\
15 & 28.62 & 1651.56 & 6.96 & 76.6 & 0.946 & 2.61 \\
20 & 27.21 & 1925.48 & 5.33 & 77.7 & 0.961 & 2.28
\end{tabular}

Results of Vicat, HDT and MFI tests

TABLE III of PP/GHS composites

\begin{tabular}{c|c|c|c}
\hline \hline GHS [wt\%] & $\begin{array}{c}\text { Vicat } \\
\text { temperature A }\left[{ }^{\circ} \mathrm{C}\right]\end{array}$ & HDT A $\left[{ }^{\circ} \mathrm{C}\right]$ & $\begin{array}{c}\text { MFI } \\
{[\mathrm{g} / 10 \mathrm{~min}]}\end{array}$ \\
\hline 0 & 155.6 & 57.2 & 6.015 \\
5 & 156.6 & 58.6 & 5.260 \\
10 & 157.3 & 62.6 & 5.241 \\
15 & 158.1 & 62.6 & 4.750 \\
20 & 159 & 66.3 & 4.347
\end{tabular}

\section{Conclusions}

The main conclusion out of this study was that the ground hazelnut shell can be used as filler in polymer based composites. Hazelnut shell conferred a characteristic brown color to resulting composites in addition to some mechanical improvement. From the results it was found that $E$ modulus, hardness, heat deflection and the Vicat softening temperature values increased with the increasing ground hazelnut content. However, tensile strength, force at break, elongation at break, the Izod impact and melt flow index values decreased. These findings were, to a certain extent, in line with the use of some inorganics fillers such as calcite and talc in polymeric matrices.

\section{References}

[1] P. Gatenholm, J. Felix, C. Klason, J. Kubat, in: Contemp. Topics Polym. Sci., Vol. 7, Springer, Boston 1992, p. 75.

[2] E. Zini, M. Scandola, Polym. Compos. 32, 1905 (2011). 
[3] F.P. La Mantia, M. Morreale, Composites Part A 42 579 (2011).

[4] H.A. Khalid, I. Artamendi, Eng. Sustainabil. 157, 37 (2004).

[5] L. Shiroma, Matéria 21, 4 (2016).

[6] M. Chaharmahali, M. Tajvidi, S.K. Najafi, Polym. Composit. 29, 6 (2008).
[7] A. Ashori, Biores. Technol. 99, 11 (2008).

[8] B.S. Gupta, I. Reiniati, M.-P.G. Laborie, Coll. Surf. A Phys. Eng. Asp. 302, 388 (2007).

[9] G. Pritchard, Reinforced Plast. 48, 26 (2004).

[10] W.M. Gramlich, D.J. Gardner, D.J. Neivandt, J. Adhes. Sci. Technol. 20, 1873 (2006). 